\title{
DITADURA E EDUCAÇÃO AGRÍCOLA: A ESALQ/USP E A “GÊNESE” DO AGRONEGÓCIO BRASILEIRO*
}

\author{
Rodrigo Sarruge Molina ${ }^{1}$ \\ José Luís SANFelice ${ }^{2}$
}

\begin{abstract}
RESUMO: Esse artigo teve por objetivo analisar as relaçôes entre a agricultura, a educação superior agrícola e a ditadura do movimento civil-militar de 1964 a 1985, tendo por foco a Escola Superior de Agricultura "Luiz de Queiroz" da Universidade de São Paulo (ESALQ/USP), eleita em 2015 a quinta melhor escola de Ciências Agrícolas do mundo. Projetada em 1881 e inaugurada em 1901, ela é uma instituição orgânica do ruralismo brasileiro e foi fundamental para fomentar as políticas agrárias dos governos militares, proporcionando as bases para a criação do agronegócio no país. Com a intervenção do governo dos Estados Unidos e grossos investimentos estatais brasileiros, a ESALQ/USP forneceu conhecimentos científicos, educacionais e de extensão rural para o processo de modernização conservadora do campo, com o regime ditatorial implementando a produção agroindustrial a "ferro e fogo" e conservando as estruturas de origem colonial, como o latifúndio e a alta exploração dos trabalhadores rurais.
\end{abstract}

Palavras-chave: Educação agrícola. Ditadura. Agronegócio. ESALQ/USP. Modernização conservadora.

\section{DICTATORSHIP AND AGRICULTURAL EDUCATION: ESALQ/USP AND THE “GENESIS” OF BRAZILIAN AGRIBUSINESS}

ABSTRACT: This article aims to analyze the relations between the dictatorship of the civil-military movement of 1964-1985, agriculture and higher agricultural education, focusing on the Agriculture University of São Paulo, Luiz de Queiroz College (ESALQ / USP), elected in 2015 the 5 th best school of agricultural sciences in the world. Designed in 1881 and inaugurated in 1901, It is an organic institution of Brazilian ruralism, and was instrumental in promoting the agrarian policies of military governments, providing the bases for

\footnotetext{
*Este artigo apresenta resultados da tese de Doutorado: "Ditadura, Agricultura e Educação: a ESALQ/USP e a modernização conservadora do campo brasileiro (1964 a 1985).”, desenvolvido no Programa de Pós-Graduação em Educação da Universidade Estadual de Campinas, financiado pela Coordenação de Aperfeiçoamento de Pessoal de Nível Superior (CAPES) e CNPq.

${ }^{1}$ Pontifícia Universidade Católica de Campinas - Campinas (SP), Brasil. E-mail: molinaprof@hotmail.com ${ }^{2}$ Universidade Estadual de Campinas - Campinas (SP), Brasil. E-mail: sanfelice00@gmail.com DOI: 10.1590/ES0101-73302018183834
} 
the creation of agribusiness in the country. With the intervention of US governments and heavy Brazilian state investments, ESALQ/USP provided scientific knowledge, educational and rural extension for the process of "Conservatory Modernization" of the Field, with the dictatorial regime implementing agroindustrial production to "blood and fire" and conserving the structures of colonial origin in Brazil, such as the latifundium and the high exploitation of rural workers.

Keywords: Agricultural education. Dictatorship. Agribusiness. ESALQ/USP. Conservative modernization.

\section{DICTATURE ET ENSEIGNEMENT AGRICOLE: L'ESALQ/USP ET LA “GÉNESIS” DE L'AGROBUSINESS BRÉSILIEN}

RESUMEN: Cet article vise à analyser la relation entre la dictature du mouvement civil-militaire de 1964-1985, l'agriculture et l'enseignement supérieur agricole en mettant l'accent sur la École Supérieur de Agriculture Luiz de Queiroz (ESALQ / USP), élu en 2015 la cinquième meilleure école des sciences agricoles dans le monde. Conçu en 1881 et inauguré en 1901, est une institution organique de la ruralité brésilienne, et a joué un role fondamental dans la promotion des politiques agricoles des gouvernements militaires, fournissant la base pour la création de l'agro-industrie dans le pays. Avec l'intervention du gouvernement des États-Unis et lourds investissements de l'Etat brésilien, l'ESALQ/USP a fourni des connaissances scientifiques, l'éducation et l'extension pour le processus de Modernisation Conservatrice du champ, avec le régime dictatorial implémentant la production agro-industrielle à "feu et à sang" et en maintenant des structures d'origine coloniale, tels que le latifundium et la forte exploitation des travailleurs ruraux.

Mots-clés: L’enseignement agricole. Dictature. Lagro-industrie. ESALQ/USP. Modernisation conservatrice.

\section{Introdução}

A

pesar de o recorte histórico estar delimitado entre os anos de 1964 e 1985, período da ditadura civil-militar, é importante alertar os leitores que o objeto de estudo, a Escola Superior de Agricultura "Luiz de Queiroz" da Universidade de Sáo Paulo (ESALQ/USP) foi projetada originalmente em 1881 e inaugurada oficialmente em 1901 pela Secretaria de Agricultura do Estado de São Paulo, sempre atendendo aos interesses da classe ruralista nacional, e em especial, a paulista.

No decorrer dos estudos, notamos o importante papel que essa unidade da USP, localizada na cidade de Piracicaba, no estado de São Paulo, desempenhou para a promoção da política agrária dos burocratas, empresários e militares 
durante a ditadura de 1964, período histórico de acentuada modernização conservadora, quando o meio rural brasileiro foi alterado com inovaçóes tecnológicas fomentadas nos laboratórios e salas de aula dessa instituição, ao mesmo tempo em que estruturas arcaicas foram conservadas e reproduzidas, como é a estrutura agrária latifundiária, os oligopólios político-econômicos, a extrema exploração dos trabalhadores e passados mais de 500 anos da conquista portuguesa, o contínuo genocídio de indígenas e negros do país.

Apesar da grande importância de se debater a violência do Estado nesse período ditatorial, o foco desse artigo é compreender as particularidades educacionais e científicas da ESALQ/USP entre os anos de 1964 e 1985 e sua contribuição para o projeto agrário dos militares — não descartando os fundamentos gerais da política, da economia ou da cultura desses "anos de chumbo".

\section{A intervenção do governo dos Estados Unidos por meio da United States Agency for International Development na ESALQ/USP}

Após o golpe de $1^{\circ}$ de abril de 1964 , o Brasil passou a ser gestado por uma aliança entre os setores civis atrelados ao capital internacional e os setores golpistas das forças armadas, que estava sob assessoramento de empresários e do governo dos Estados Unidos. Com o acirramento da Guerra Fria, na década de 1950, e após a Revolução Cubana, de 1961, os EUA passaram a intervir com mais radicalidade na América Latina, fomentando uma série de golpes de Estado e governos ditatoriais, impactando o Brasil, a Guatemala, o Paraguai, a Argentina, o Uruguai, o Paraguai, o Equador, o Peru, a Bolívia, o Chile, entre outros países. Tal postura do imperialismo estadunidense era amparada pelo discurso clássico intervencionista: "proteger o mundo e a democracia" — naquele período, contra a influência comunista. A mesma justificativa política era utilizada pelas elites nacionais desses países latino-americanos para a implantação de regimes autoritários.

Assim, o imperialismo interveio no financiamento, na comercialização da produção e no transporte dos produtos, legitimando-se pela ideologia, por intermédio de agências públicas ou privadas. Como veremos adiante, um dos campos de atuação dessa doutrinação foram as instituiçóes escolares.

No campus USP de Piracicaba, destacou-se a interferência direta da Agência dos Estados Unidos para o Desenvolvimento Internacional (United States Agency for International Development - USAID $)^{1}$ por meio de um convênio, assinado em abril de 1963 e colocado em prática em 1964, entre a Ohio State University (OSU) e a ESALQ/USP (especialmente entre os anos de 1964 e 1973). $\mathrm{O}$ item II do acordo binacional estabelecia: "adaptar o ensino, a pesquisa e a educação do lavrador na ESALQ, ao padrão do sistema norte-americano de Land Grant Colleges" (CAPDEVILLE, 1991, p. 98). 
Grosso modo, o sistema de Land Grant Colleges pensado para as escolas agrícolas é originário da reforma agrária estadunidense na transição dos séculos XIX e XX. Naquela época, o plano objetivou fomentar um sistema integrado e federal de escolas agrícolas que atendesse aos interesses dos diferentes tipos de produtores rurais, aperfeiçoando especialmente a produção familiar por meio da cooperação entre as diversas unidades científicas e educativas dos municípios, montando um sistema federal de colaboração para a disseminação do manejo racional das primeiras máquinas agrícolas, dos insumos e a administração empresarial das fazendas.

Visando a implantar esse sistema educacional capitalista dos EUA no Brasil, grande parte do trabalho de cada membro do grupo da OSU-USAID foi direcionado para três áreas: pesquisa, ensino e extensão. No entanto, conforme relataram os estadunidenses em documentos, a introdução desse sistema tinha uma espécie de resistência "cultural" por parte dos brasileiros, seja "consciente ou inconsciente". Segundo os estrangeiros, para corrigir esse bloqueio, seria necessário insistir em um trabalho "árduo" de toda a equipe dos Estados Unidos em São Paulo visando "quebrar barreiras imaginárias e reais" que eram preocupantes, pois cresciam entre os "diversos segmentos da equipe de profissionais". Os técnicos estrangeiros chegaram a lamentar-se de forma preconceituosa, afirmando que os professores da ESALQ/USP pareciam não corresponder aos investimentos "pagos com verbas públicas" para transformar a agricultura do país (USAID/ESALQ, 1964, p. 34-35).

$\mathrm{Na}$ realidade, os norte-americanos não compreendiam que, além da resistência cultural dos professores da ESALQ/USP, a base material brasileira era diversa. O sistema produtivo aqui era um capitalismo de periferia, baseado historicamente em uma colônia de exploração e com todos os problemas decorrentes do processo civilizatório lusitano. Não seria possível simplesmente transplantar mecanicamente um projeto planejado para operar em um capitalismo central de matriz imperialista e que havia feito a reforma agrária, para um Brasil marcado pela sua origem "colonial-dependente" e com uma estrutura agrária praticamente "intacta" e, por isso, oligárquica e latifundiária. $\mathrm{Na}$ realidade, no início dos convênios, a falta de compreensão histórica fez com que os professores de Ohio propusessem soluçóes "engessadas" para a educação agronômica brasileira que não funcionaram conforme o script proposto pelo governo estadunidense.

Segundo dados bibliográficos de 1975, esse convênio entre estadunidenses e esalqueanos ${ }^{2}$ proporcionou a visita de professores dos EUA a Piracicaba, os quais permaneceram por tempo variável de 2 meses a 4 anos. $\mathrm{O}$ mesmo acordo internacional possibilitou a viagem de professores da "Luiz de Queiroz" às universidades norte-americanas, especialmente para cursarem mestrados e doutorados (ESALQ75, 1975, p. 130). 
O grande projeto do intercâmbio foi montar um intenso programa de pós-graduaçáo na "Luiz de Queiroz" e, para isso, foram fornecidos recursos financeiros e materiais para equipamentos de laboratório e outras "facilidades" (USP, 1964b).

Em 1964, no princípio do convênio USAID-ESALQ, foi feito um estudo minucioso da situação agrícola do estado de São Paulo pelos técnicos da Universidade Estadual de Ohio. Como resultado da análise, os estadunidenses traçaram as seguintes diretrizes gerais do intercâmbio: desenvolvimento de um projeto piloto para o estado de São Paulo; treinamento de supervisores do fomento; revisão dos currículos da escola, especialmente do recém-inaugurado curso superior em economia doméstica (1966); e análise e atenção ao curso de sociologia rural e extensão (USP, 1965).

Os estudos demonstram que, após a liberação de verbas fornecidas pela USAID para a ESALQ/USP, foi instalado um escritório dos representantes dos Estados Unidos no campus de Piracicaba. Ambas as instituiçóes traçaram um plano para além dos muros da "Luiz de Queiroz" e passaram a intercambiar com várias áreas da educação, pesquisa e produção agrícola. Assim, foram estabelecidos contatos com os profissionais dos vários institutos de pesquisa, como o Instituto Agronômico de Campinas (IAC), instituiçóes escolares como o caso da Universidade Rural do Estado de Minas Gerais (hoje UFV), as diversas divisões da Secretaria de Agricultura do Estado de São Paulo, fazendas, empresas e indústrias.

Por meio dos documentos, constatamos que os norte-americanos precisavam convencer os brasileiros, afirmando que objetivavam "aperfeiçoar" o modo de produçáo dos proprietários rurais e seus trabalhadores por meio de um plano coletivo de tarefas que implantasse um "programa energético de educação elevada". Pesquisas também seriam dirigidas propondo solucionar problemas agrícolas importantes, especialmente em um "esforço coordenado" para informar os lavradores sobre as maneiras e meios de aumentar a produção e sua renda líquida (USAID/ESALQ, 1964).

Os financiamentos e o suporte técnico dos Estados Unidos via USAID, fundação Rockfeller e fundação FORD, que já ocorriam desde a década de 1950 e foram aprofundados durante a ditadura militar, diminuíram consideravelmente após a crise econômica mundial de 1974.

\section{Os generais no campus "Luiz de Queiroz" de Piracicaba}

Apesar de os dólares fazerem falta para professores e estudantes, que utilizavam esses recursos para realização de intercâmbios internacionais, compra de equipamentos e colaboração técnica via extensão rural, o Estado brasileiro se fez presente e suportou a maior parte dos projetos da instituição após o distanciamento com os Estados Unidos, em 1973. Nesse período, o Estado foi fundamental para 
o fomento da agroindústria brasileira, e um exemplo bem-sucedido foi o programa Proálcool ${ }^{3}$. Aliás, apesar da presença do governo dos Estados Unidos e empresas dentro da escola, os relatórios da ESALQ/USP nos revelaram que, durante toda a ditadura civil-militar, a maior parte dos investimentos em pesquisa, educação e extensão foi realizada pelo Estado brasileiro, que multiplicou os financiamentos entre os anos de 1968 e 1973, apresentando uma tendência de valorização até 1980. Esses financiamentos privilegiaram principalmente as ciências aplicadas ${ }^{4}$, o que beneficiou diretamente a "Luiz de Queiroz", pois o foco da instituiçẫo estava em seus cursos de Agronomia, Engenharia Florestal, Economia Doméstica ou mesmo suas pesquisas com Genética e Energia Nuclear.

Além da grande injeção de recursos federais e estaduais, na ESALQ/USP a presença do "regime militar" também se fazia presente nas formaturas da escola, tradicionalmente frequentada pelas elites brasileiras, especialmente a classe ruralista. Esse entrosamento entre ditadores, agricultores e acadêmicos é compreensível, pois de acordo com Octavio Ianni (1979), entre as classes subalternas, a classe média foi a única que recebeu alguma recompensa como forma de renda complementar pela ditadura em retribuição a seu apoio ao golpe de 1964 e a sustentação política em seus 21 anos de governo (IANNI, 1979, p. 26).

Nesse contexto, o ditador Emílio Garrastazu Médici foi convidado pelos alunos esalqueanos para ser o paraninfo da turma de agronomia de 1971, fato noticiado com euforia pela imprensa da época, como estratégia de propaganda do regime (JORNAL DE PIRACICABA, 1971). Na ocasião, Médici aproveitou para inspecionar o Centro de Energia Nuclear na Agricultura, o Departamento de Genética e o Departamento de Silvicultura, quando foi surpreendido por centenas de esalqueanos, dos quais 13 vestiam as camisas do Projeto Rondon e exibiam faixas em que se lia, por exemplo, "Obrigado, Presidente da Juventude" (ESTADÁO, 1971). Na reportagem, lê-se: "Em frente ao edifício principal da escola, o presidente cumprimenta estudantes do Projeto Rondon" (ESTADÁO, 1971) que atuaram na região de Rio das Pedras, Analândia e Itupeva. Ainda, segundo a imprensa, o diretor da ESALQ, Ferdinando Galli afirmou: "Achamos que a presença do presidente Médici na ESALQ é sobremaneira honrosa e é motivada pelo renome deste estabelecimento de ensino. Ser o Presidente o paraninfo de nova turma de engenheiros agrônomos nos deixa sumamente satisfeitos" (DIÁRIO, 1971).

Apesar da propaganda favorável ao regime na imprensa e na escola, podemos constatar que, nas universidades, o Projeto Rondon e outras práticas extensionistas visavam a legitimar o poder da ditadura por meio da cooptação dos jovens que seriam a vitrine do governo em projetos sociais. Nessa época, por meio do assistencialismo e o paternalismo, Médici foi desenhado como o grande chefe e comandante de uma nação que estaria crescendo para um futuro glorioso. $\mathrm{Na}$ época, o slogan propagandista da ditadura resumia a proposta do governo Médici: "Ninguém mais segura esse país" ou "Brasil, ame-o ou deixe-o". 
Outro presidente que visitou a ESALQ nos "anos de chumbo" foi Ernesto Beckmann Geisel, que esteve no campus de Piracicaba em 19 de dezembro de 1973. A comitiva técnica do general era composta por 16 homens, entre políticos, militares e acadêmicos que foram se reunir para um banquete na casa do diretor Galli. A residência oficial do diretor era uma grande mansão ${ }^{5}$ dentro do campus, abastecida por vários empregados, uma espécie de "Palácio da Alvorada" da USP de Piracicaba, pois além de servir de residência para o diretor e sua família também concentrava uma série de atividades acadêmicas e políticas (DIÁRIO, 1973).

Segundo a imprensa da época, após essas "formalidades", entre regalos e exposiçóes de trabalhos, foi programada uma conversa reservada entre o general e os alunos por cerca de 40 minutos. Após a prosa e saindo, Geisel acenou para os estudantes dizendo: "Está bem, senti muita satisfação em falar com vocês" (JORNAL DE PIRACICABA, 1973).

No mesmo dia da visita de Geisel, ocorria a formatura da turma de 1973. Em entrevista à imprensa da cidade, o então secretário da Agricultura do Estado de São Paulo, Araujo Dias, aproveitou a ocasião para relatar os desejos de sua pasta com relação à nova safra de esalqueanos daquele ano: desejava-se que a "Luiz de Queiroz" graduasse agrônomos que fossem um misto de técnicos especializados e capatazes tradicionais para auxiliar as diferentes formas de trabalho que existiam no campo.

Ou seja, buscava-se formar técnicos especializados — para auxiliar na região centro-sul (o Brasil rico e moderno com máquinas e demais insumos) e capatazes "tradicionais" - para lidar com as regiōes "hostis" e pobres (como a Amazônia). A depender da área de atuação do agrônomo, este deveria adequar-se aos diferentes sistemas de trabalho, atuando também como divulgador das técnicas científicas e, sobretudo, da consciência e responsabilidade social de "verdadeiros agentes do desenvolvimento agrícola nacional" (JORNAL DE PIRACICABA, 1973).

$\mathrm{Na}$ ocasião da visita de Geisel, foi programada uma inspeção na pós-graduação, um dos principais focos de investimentos do regime na ESALQ. Foram visitados os departamentos de Silvicultura, para explicaçôes sobre a Engenharia Florestal; o departamento Técnico Rural, no qual se familiarizou com as pesquisas desenvolvidas com o açúcar e o álcool, o departamento de Genética e o Centro de Energia Nuclear na Agricultura (CENA).

\section{A criação da Pós-Graduação da ESALQ/USP em 1964}

Durante a ditadura civil-militar, a criação dos programas de pós-graduação foi uma das prioridades dos tecnocratas educacionais e economistas. Principalmente na década de 1970, por meio de altos investimentos, as universidades 
auxiliaram os governos militares na implantação do projeto político-econômico de modernização conservadora ${ }^{6}$, ou seja, introdução de tecnologias avançadas e a conservação da miséria brasileira.

Eram planos de avanço capitalista, como foram os famosos Planos Nacionais de Desenvolvimento (PND) - I PND (1972-1974) e o II PND (1975-1979) - que reservavam especial atenção para a expansão científica e educacional. "Para que a economia crescesse no ritmo desejado, eram necessários mais especialistas, técnicos e, se possível, novas tecnologias” (MOTTA, 2014, p. 255), daí a priorização na expansão de programas de pós-graduação e cursos de graduação, como os que ocorreram na ESALQ/USP.

Do ponto de vista político, esse período foi caracterizado por certo consenso social, especialmente na universidade, quando muita gente foi cooptada com elevação salarial, reestruturação da carreira docente, aumento do financiamento para a pesquisa e a ampliação de vagas nos cursos de graduação, o que agradou às classes médias. Porém, ao mesmo tempo, foram tempos obscuros e totalitários, pois ocorreu grande controle ideológico e repressáo física contra a oposição política aos governos militares, com aposentadorias compulsórias, demissóes, perseguições, torturas e assassinatos, como foi o caso do esalqueano Luiz Hirata e da professora do Instituto de Química da USP, Ana Rosa Kucinski Silva.

Dentro dessa conjuntura de cooptação, coerção e repressão ditatorial, a ESALQ/USP inaugurou, em 1964, o estratégico curso de pós-graduação em Ciências Agronômicas, articulado com o governo dos Estados Unidos e sob assessoramento do Conselho Interamericano Cultural de Organização dos Estados Americanos (OEA), que elencou a escola como um dos centros multinacionais para a pós-graduação em Ciências Agrícolas. No período, cursos com nomes e conteúdo semelhantes aos da "Luiz de Queiroz" eram desenvolvidos na Inglaterra, Estados Unidos, Argentina, Chile, México e Peru, o que demonstra um projeto integrado e influenciado por organismos internacionais ${ }^{7}$ (USP, 1968).

Contraditoriamente, enquanto existiam as interferências imperialistas, o discurso político dos militares fomentava o nacionalismo do "Brasil Grande", a suposta potência sul-americana que seria vanguarda na modernização, sendo que a pós-graduação (ciência e tecnologia) era uma das bases táticas para esse progresso capitalista (SAVIANI, 2008).

Nesse contexto, em 15 de setembro de 1964, foram instalados seis cursos conferindo o título de Magister Scientiae nas áreas de Experimentação e Estatística, Fitopatologia, Genética e Alteração de Plantas, Mecânica, Motores e Máquinas Agrícolas, Nutrição de Plantas, e Solos (USP, 1964a).

Em 1969, o Conselho Nacional de Desenvolvimento Científico e Tecnológico $(\mathrm{CNPq})$ declarou a ESALQ centro de excelência para o desenvolvimen- 
to de programas de ensino de pós-graduação e pesquisa em Ciências Agrárias. Em 1970, os cursos de Fitopatologia, Genética e Alteração de Plantas e Solos e Nutriçẫo de Plantas passaram a oferecer o nível de doutorado.

Em 1975, o professor Eurípides Malavolta afirmou que a ESALQ/USP foi uma das primeiras instituiçóes do Brasil a articular pesquisas integradas "discutindo o assunto em seminários de pesquisa agrícola patrocinado conjuntamente pelo CNPq e pela National Academy of Sciences dos EUA" (ESALQ75, 1975, p. 55). "Dentro dessa parceria surgiram diversos projetos", com destaque para pesquisas sobre mutaçôes com o milho (MOLINA, 2016, p. 284).

Todos esses esforços para a formaçáo de mestres e doutores serviam para aumentar a produção de ciência visando à solução de problemas específicos do país, fator fundamental para o crescimento econômico das empresas agrícolas nacionais e multinacionais aqui instaladas. No geral, esses pós-graduandos de Piracicaba iriam alimentar a expansão de agroindústrias, universidades e institutos estatais, como a Empresa Brasileira de Pesquisa Agropecuária (EMBRAPA), fundada em 1973, que tinha carência de máo de obra especializada, pois, de seus 830 pesquisadores, apenas $17 \%$ tinham pós-graduaçáo, sendo somente dois doutores. "À época, a Diretoria da Embrapa decidiu dar prioridade à capacitação de seus técnicos em escolas estrangeiras e brasileiras, entre as quais figurou a ESALQ" (DEMÉTRIO; VIEIRA, 2004, p. 25).

\section{A mutação de plantas no estratégico departamento de genética}

Nesse período de crescimento da pós-graduação, um dos principais fomentos da educação e pesquisa agrícola no período do Regime Militar foi a genética. Por meio da genética, os cientistas esalqueanos criaram o chamado "Centralmex, o Super Milho". Essa variedade de milho sintético foi criada a partir da união de milhos de diversas qualidades que tivessem condições agronômicas e comerciais boas, a partir dos quais era selecionada uma variedade comum, por meio de métodos da ciência genética (JORNAL DE PIRACICABA, 1971).

Segundo os pesquisadores defenderam, o milho mutante era vantajoso para a agroindústria, pois poderia ser plantado diversas vezes sem perda de produtividade. Além disso, servia como base para companhias particulares na produção de milhos cada vez mais produtivos, beneficiando a modernização capitalista dos campos brasileiros. Apesar do grande interesse das companhias nacionais e multinacionais na produção do "supermilho", procurava-se convencer toda a sociedade da importância do projeto. Para isso, um estudo da escola, financiado pelo Ministério da Agricultura, pretendia legitimar o uso do milho sintético como o mais vantajoso para toda a sociedade agrícola, especialmente para os lavradores comuns que não dispunham de assessoramento técnico, pois o "supermilho" desenvolvido 
em Piracicaba seria mais resistente a doenças, aumentando a produtividade de todos os produtores agrícolas e diminuindo a necessidade de auxilio agronômico (JORNAL DE PIRACICABA, 1971).

Até 1971, as sementes desse milho aperfeiçoado no campus USP de Piracicaba foram levadas para praticamente todo o Brasil, como as unidades federativas do Mato Grosso, Goiás, Pará, Pernambuco, Minas Gerais; havia um plano para introdução de plantações com este "Supermilho" na região Amazônica. Planejava-se também transferir outro gene descoberto nos Estados Unidos para a variedade obtida em Piracicaba, principalmente para a nutrição humana, com grandes resultados na aplicação de rações para alimentação de animais confinados (JORNAL DE PIRACICABA, 1971).

Com a ascensão dessas produçôes high tech de exportação, a produção de alimentos para a população brasileira foi afetada e o custo de vida encarecido, especialmente nos grandes centros urbanos. Por isso, visando a contornar esses problemas políticos e econômicos do capitalismo desenvolvido nessa periferia sul-americana, aumentando a produçáo de alimentos por todo o Brasil (com exceção da Amazônia), a ESALQ desenvolveu hortaliças geneticamente modificadas. $\mathrm{Na}$ época, foram firmados convênios de colaboração técnica e cientifica com Cooperativas Agrícolas de São Paulo (Cotia, Sul-Brasil e Mogi), com entidades do Rio Grande do Sul e com a Superintendência de Desenvolvimento do Nordeste (SUDENE); em 1971, as pesquisas atingiam diretamente milhares de famílias produtoras e cooperadas. Além de distribuir sementes geneticamente modificadas aos lavradores, a instituição uspiana também realizava, por meio de seus estudantes e professores, assistência técnica de infraestrutura, ensinando os produtores como usar o pacote modernizador nos campos (JORNAL DE PIRACICABA, 1971).

\section{A educação e pesquisa com energia nuclear aplicada à agricultura}

Dentro desse processo histórico de modernização conservadora, encontravam-se os planos militares com a energia nuclear, como foi a construçáo de usinas de energia elétrica em Angra dos Reis (RJ), o projeto militar de construção de uma bomba atômica e também a educação e as pesquisas sobre a aplicação da radiaçáo na agricultura para o fomento da agroindústria (MOLINA, 2016). Para isso, em 22 de setembro de 1966, foi inaugurado o Centro de Energia Nuclear na Agricultura (CENA) no campus USP de Piracicaba, compreendendo uma área de $9.800 \mathrm{~m}^{2}$.

No entanto, apesar do projeto "nacionalista", as potências ocidentais capitalistas guardavam os desenvolvimentos com energia atômica em Piracicaba com especial atenção. Em maio de 1971, uma comitiva da Organização das 
Nações Unidas (ONU), dirigida pelos estadunidenses Cyril Lewis Comar (Cornell University) e Sylvan Wittwer (Michigan State University), veio inspecionar os trabalhos com energia nuclear do CENA. Após esse controle, um convênio foi aprovado em 1972 entre a Comissão Nacional de Energia Nuclear (CNEN) e a United Nations Development Programme (UNDP), administrado pela Agência Internacional de Energia Atômica, para o desenvolvimento de pesquisas de tecnologia nuclear aplicada à agricultura. Esse convênio, projetado para cinco anos, previa um financiamento de 1,3 milhóes de dólares, sendo uma parte do governo brasileiro e outra das agências internacionais, determinando um intercambio científico multinacional para formar os técnicos uspianos, seja por meio da visita dos cientistas estrangeiros a Piracicaba, seja pelo envio de bolsistas nacionais ao exterior para aperfeiçoamento. Como consequência desse convênio, batizado de "Projeto BRA/71/556", funcionou no CENA, até 1991, o único escritório exclusivo da Agência Internacional de Energia Atômica na América Latina fora das embaixadas, sob forte hegemonia estadunidense (LEÃO, 1997, p. 87).

Durante as décadas de 1960 a 1970, além dos investimentos internacionais, entre os principais financiadores nacionais destacaram-se a Comissão Nacional de Energia Nuclear (CNEN) e, em especial, a Financiadora de Estudos e Projetos (FINEP), pertencente ao Ministério do Planejamento. A FINEP, entre os anos de 1969 a 1974, chegou a representar cerca de 50\% do orçamento do CENA (ESALQ75, 1975, p. 234).

Os principais projetos de pesquisa durante a ditadura foram concentrados no fomento da agroindústria, com experimentos com soja, café, trigo, canade-açúcar e eucalipto.

Em 1971, o diretor do CENA, Admar Cervellini, ressaltou em entrevista ao Jornal de Piracicaba que o Centro proporcionaria aos agricultores uma ferramenta chamada bomba de cobalto, que poderia eliminar os insetos prejudiciais às plantaçóes e criar novas variedades resistentes a pragas e agrotóxicos (JORNAL DE PIRACICABA, 1971).

Para além das pesquisas, o CENA também atuava na área da educação para a formação de seus técnicos. Corria o ano de 1964, quando o centro ofereceu o curso latino-americano de Radioisótopos na Agricultura, contando com 20 matrículas, 14 latino-americanos e 6 brasileiros. Foi nessa época que, juntamente com o programa de pós-graduação, criou-se o Curso de Introdução à Energia Nuclear na Agricultura. Com duração de dois anos, o curso era voltado para os alunos do segundo ano da agronomia da ESALQ e ofertado no período noturno. No período das férias, funcionava em regime integral (LEÃO, 1997, p. 171).

Outro trabalho que o CENA procurou desenvolver foi a assistência técnica direta aos produtores rurais por meio de cursos, palestras e trabalhos de extensão, pois como afirmou o diretor do instituto à imprensa "não basta colocar 
o adubo, é necessário administrá-lo na medida correta, com a proporção devida e no local e época adequados" (JORNAL DE PIRACICABA, 1971).

Em 1977, o CENA deixou de ser um simples departamento da ESALQ e ganhou o status de Centro de Estudos Especializados, com autonomia e independência. Em 1985, juntamente com a ESALQ, o CENA passou a integrar o campus "Luiz de Queiroz", mas manteve sua autonomia. Em 1988, em decorrência de uma reestruturação interna, o CENA foi incluído como instituto especializado da Universidade de São Paulo. Atualmente conta com 37 professores contratados, dos quais 7 titulares, 18 associados e 12 doutores.

\section{Diversificação da graduação e a reforma universitária na ESALQ}

Desde sua fundação, em 1901, a “Luiz de Queiroz” já graduou 14.647 profissionais da área das Ciências Agrícolas. Porém, a ampliação da área da graduação foi iniciada em 1967, com a inauguração do curso de Economia Doméstica, com 20 vagas e em 1968 iniciou-se o curso de Engenharia Florestal.

Em 1969, a Reforma Universitária de 1968 foi implantada na ESALQ/USP. Após 70 anos de existência, o curso de Agronomia e suas disciplinas receberam uma nova seriação. Nesse período, foram criadas novas matérias e uma seriação de disciplinas, "a base de pré-requisitos, em que, através de uma sucessão natural, disciplinas básicas eram sucedidas paulatinamente, por disciplinas de formação profissional" (ESALQ75, 1975, p. 128).

Foi nesse momento que a ESALQ e o conjunto da Educação brasileira foram afetados pelo tecnicismo em prejuízo da ciência pura. Foi instituído o sistema de créditos acabando com a tradição das turmas, fragmentando e desmobilizando a formação coletiva dos alunos. Agora, o aluno individualmente deveria "conquistar" seu diploma cumprindo um determinando número de créditos, em disciplinas essenciais ou obrigatórias e a parte restante em disciplinas eletivas, escolhidas individualmente pelo aluno, de acordo com seus interesses particulares (ESALQ75, 1975, p. 128).

De acordo com Saviani (2008, p. 306-307), a criação dos departamentos e a matrícula por disciplina por meio do sistema de créditos colaborou para a generalização dos cursos de ensino superior parcelados, "transpondo para a universidade o parcelamento do trabalho introduzido nas empresas pelo taylorismo".

Essas reformas preocupavam-se com a racionalizaçáo dos custos - ou melhor, com a redução dos custos. Assim, o novo sistema de créditos afetou a qualidade do ensino, pois a eliminação das turmas (classes) e a criação dos departamentos dificultaram o trabalho personalizado dos professores com os alunos durante a trajetória formativa dos estudantes. Agravou esse quadro a superlotação das 
salas (sem contratação de novos docentes), com alunos de diferentes habilitaçóes em uma mesma classe, o que gerou cursos que não consideravam as particularidades das diferentes carreiras profissionais.

Outro fator de precarização foi o processo de aceleração do período letivo com a substituição do anual pelo semestral, dificultando o trabalho pedagógico dos docentes com os estudantes. Segundo Saviani, isso inviabiliza "a superação das eventuais lacunas e dificulta a assimilaçáo efetiva, pelos alunos, dos conhecimentos constitutivos das disciplinas consideradas indispensáveis à sua formação" (SAVIANI, 2008, p. 306-307).

Também como reflexo da Reforma Universitária e da influência pedagógica estadunidense para as ciências agrárias, em 1969 ocorreu mudança radical na metodologia de ensino, que consistia na constante avaliação dos professores e alunos por meio de questionários programados para leitura de respostas via computação eletrônica. Docentes e discentes eram livres para expressar sua opinião sobre o desempenho de uns e de outros e sobre o conteúdo das disciplinas. As informaçóes processadas pelos computadores eram analisadas por uma comissão interna e enviadas aos departamentos para possíveis alteraçōes dos programas de ensino (ESALQ75, 1975, p.49).

$\mathrm{Na}$ época, a reforma implantada pela ditadura, mas já desenhada à direita pré-1964, tinha o objetivo de não reformar as universidades no sentido dos interesses da população, mas torná-las máquinas eficientes e produtivas, com o fim de aperfeiçoar a força de trabalho para fomentar a modernização capitalista, tanto na iniciativa privada como na burocracia estatal (MOTTA, 2014, p. 70). Para que isso ocorresse, o Ministério do Planejamento tinha precedência sobre o da Educação na elaboração da planificação educacional do país (SAVIANI, 2008, p. 295).

Uma das ideologias que legitimava esse processo era a "teoria do capital humano", que, rigorosamente, acredita no valor da educação como investimento particular direcionado à ampliação da acumulação capitalista privada, ou seja, é a compreensão da educação como uma mercadoria que deve ser consumida para acrescentar conteúdo aos currículos dos trabalhadores em um contexto de grande competitividade no mercado de trabalho. A predominância dessa visão tecnicista passou a disseminar a ideia de que a educação é o pressuposto do desenvolvimento econômico, bem como do desenvolvimento do indivíduo, que, ao educar-se, estaria "valorizando" a si próprio, na mesma lógica em que valoriza o capital (MINTO, s.d.).

Nesse contexto ditatorial, a ideologia do "capital humano" esteve presente em toda a ESALQ/USP, como, por exemplo, no curso de Economia Doméstica inaugurado em 1967 com o auxílio de técnicos da USAID. Em 1984, em depoimento à revista do Centro Acadêmico Luiz de Queiroz (CALQ), uma 
representante discente do curso, Patrícia Maria de Campos, relatou que o objetivo do curso era aplicar integralmente os conhecimentos de ciência, tecnologia e arte para orientar as famílias brasileiras na "utilização racional de recursos materiais e humanos, buscando seu desenvolvimento harmônico num contexto físico, social, econômico e cultural". Um dos focos do curso era a educaçáo do consumidor (CAMPOS, 1984, p. 34).

Concomitantemente ao curso de economia doméstica, à ideologia do capital humano, à reforma universitária e ao pensamento conservador, a ditadura criou a "lei do boi" por meio do Decreto no 5.465 , de 3 de julho de 1968, que estabeleceu cotas nos cursos de agronomia para os filhos dos "trabalhadores rurais". O uso das aspas é proposital, pois embora a lei mencione os filhos dos "trabalhadores rurais" como cotistas, na prática a lei beneficiou os filhos dos proprietários rurais. $\mathrm{Na}$ realidade do mundo rural, os filhos dos trabalhadores rurais eram em grande parte analfabetos e trabalhavam com seus pais no plantio e na colheita, sem oportunidades de frequentar as escolas do ensino básico.

Foi assim que o dispositivo ditatorial, em sintonia com os grandes fazendeiros e a agroindústria, articulou esse sistema de cotas que reservava $50 \%$ das vagas nas instituições de ensino médio e superior da área de agricultura e veterinária, mantidos pela União, aos filhos de "trabalhadores rurais". Na prática, liberou as vagas aos filhos de grandes fazendeiros e proprietários rurais de médio porte e excluiu do processo os verdadeiros trabalhadores rurais, os filhos pobres de camponeses que necessitavam vender sua força de trabalho a crescente agroindústria, como eram os boias-frias. Se na época essas crianças e adolescentes mal conseguiam se alfabetizar, a universidade sempre foi um sonho distante e reservado aos herdeiros da casa-grande (ALMEIDA, 2010).

Porém, como veremos a seguir, as universidades públicas também sofreram com ingerências do setor privado por meio das "fundaçóes".

\section{Fundação de Estudos Agrários Luiz de Queiroz: 1976}

Durante os anos 1970, com incentivos do governo federal para as universidades concorrerem com mais facilidades às verbas das diversas agências estatais e privadas, muitas universidades públicas criaram as "fundações de apoio à pesquisa", visando a atingir a eficiência exigida pela dinâmica das agências financiadoras, nacionais e internacionais.

Originalmente, o que se esperava das fundaçóes era a desburocratização das universidades, visando facilitar a entrada de verbas para as instituiçóes, "já que, em princípio, estavam livres das normas do serviço público e prometiam também eficiência na gestão dos projetos de pesquisa” (MOTTA, 2014, p. 262). Outro fator que animou seus apologistas foi a entrada de dinheiro diretamente nas 
fundaçóes que repassariam automaticamente aos pesquisadores, racionalizando a moeda para as pesquisas, pois o controle das finanças era antes monopolizado pelas reitorias e que geralmente se apossavam do dinheiro destinado para a pesquisa e o revertia para outros fins (MOTTA, 2014, p. 262).

Segundo Minto (2014, p. 248), durante a ditadura essas fundaçóes faziam parte de uma estratégia para transformar as universidades (que eram majoritariamente autarquias) em fundaçóes de direito público ou privado dentro de uma estratégia de desburocratização das mesmas. No entanto, a gênese desse processo é anterior à ditadura, seu desenho já pode ser visto com os princípios que orientaram a Lei de Diretrizes e Bases (LDB - 1961) e aprofundados com a reforma universitária de 1968, a Lei no 5.692/1971 e com a regularização da pós-graduaçáo com o "Parecer Sucupira" de 1975.

Conforme Sguissardi (1993, p. 35), essas fundaçōes universitárias foram pensadas para ter uma dupla função no processo de desregulamentação da obrigação do Estado com a educação superior. Primeiro por meio do incentivo da iniciativa privada na educação e contenção da expansão das instituiçóes de ensino superior estatais e, em segundo lugar, "recuperação do controle político-administrativo sobre a universidade" (SGUISSARDI, 1993, p. 35).

Além da crescente criação de empresas educacionais, ou universidades privadas, as fundaçóes também estavam sintonizadas com a crescente privatização da educação pública brasileira, pois foi uma "tentativa de o Estado desobrigar-se do ponto de vista econômico-financeiro com a manutenção do Ensino Superior e aumentar o seu poder de intervenção (sobre as Instituiçóes de Ensino Superior)" (SGUISSARDI, 1993, p. 36).

Na ESALQ, esse processo foi materializado com a criação da Fundação de Estudos Agrários Luiz de Queiroz (FEALQ). Inaugurada em 1976, a entidade privada funciona como captadora de recursos externos para promover programas de pesquisa científica, publicaçóes, eventos e cursos que atendem aos interesses da agroindústria.

Essa entidade, segundo denúncias da Associação dos Docentes da Universidade de São Paulo (ADUSP), nos anos subsequentes a 1978, tinha "um poder único", pois "todos os diretores eleitos até 2003 possuíam ou possuem ligaçōes estreitas com a FEALQ" (ADUSP, 2004, p. 4). Entre 1978 e 1981, "foram realizados os primeiros cursos pagos em parceria com a fundação" com a participaçáo de docentes da ESALQ/USP (ADUSP, 2004, p. 4).

Assim, a instituiçáo "pública", junto à entidade privada FEALQ, também atua no mercado da educação ao promover cursos pagos na chamada extensão universitária. Com a oferta de cursos presenciais, semipresenciais ou "a distância" nas dependências da ESALQ. 
Esse processo de mercantilização da universidade teve aprofundamento durante a ditadura civil-militar de 1964, pois,

\begin{abstract}
para além desse fortalecimento do setor privado do ensino, cabe considerar, também, que o próprio setor público foi sendo invadido pela mentalidade privatista, traduzida no esforço em agilizar a burocracia aperfeiçoando os mecanismos administrativos das escolas; na insistência em adotar critérios de mercado na abertura dos cursos e em aproximar o processo formativo do processo produtivo; na adoção dos parâmetros empresariais na gestão do ensino; na criação de "conselhos curadores", com representantes das empresas, e na inclusão de empresários bemsucedidos como membros dos conselhos universitários; no empenho em racionalizar a administração do ensino, enxugando sua operação e reduzindo seus custos, de acordo com o modelo empresarial. (SAVIANI, 2008, p. 300).
\end{abstract}

Na ESALQ/USP, os cursos pagos ofertados em 2011 eram: Gerenciamento Ambiental; Manejo do Solo; Produção de Ruminantes; Matrizes; MBA em Agronegócios; Noçôes de Probabilidade; Investimento, Planejamento e Gestáo no Complexo Agroindustrial Sucroalcooleiro; Cálculo Diferencial e Integral; Métodos Estatísticos Multivariados; Técnicas de criação de insetos para programas de controle biológico com ênfase à comercialização de inimigos naturais; Atualização: dinâmica da matéria orgânica do solo no agrossistema cana-de-açúcar no Brasil; C e N no solo e emissão de gases do efeito estufa; e Gestão da Logística Agroindustrial ${ }^{8}$.

A seguir, veremos como essas articulaçóes entre a ESALQ e o agronegócio foram aprofundadas nas décadas de 1970 e 1980, especialmente com a fundação do Centro de Estudos Avançados em Economia Aplicada (CEPEA).

\title{
O Centro de Estudos Avançados em Economia Aplicada: 1982
}

Estudar a história do CEPEA durante a ditadura é compreender as relaçóes entre a ditadura civil-militar e a constituiçâo do agribusiness no Brasil. Apesar de ter suas origens no antigo "Centro de Pesquisa em Economia Agrícola", na década de 1970, o CEPEA foi inaugurado oficialmente em 1982 como parte integrante do Departamento de Economia, Administração e Sociologia. Segundo informações oficiais do sítio virtual do CEPEA, na década de 1980, os primeiros financiadores que contrataram pesquisas no centro foram entidades nacionais como a Secretaria de Indústria e Comércio de São Paulo, o CNPq, a FINEP e a Fundação de Amparo à Pesquisa do Estado de São Paulo (FAPESP). O principal financiador internacional foi o Banco Mundial, sob hegemonia dos Estados Unidos.

Portanto, o CEPEA foi forjado para ser um dos braços do agronegócio no Brasil, cujo principal objetivo é realizar pesquisas diárias sobre os produtos 
agropecuários e seus derivados visando à elaboração de indicadores de preços dos produtos, insumos e serviços do mercado rural, que são referência para a Bolsa de Mercadorias e Futuros (BM\&F) e para as publicaçóes da Agência Estado (Grupo ESTADO - O Estado de São Paulo), especialista em informaçóes para o mercado financeiro. "Desde fevereiro de 1999, o CEPEA está sediado no prédio construído ao lado do Pavilhão de Engenharia da ESALQ/USP. A BM\&F foi a principal patrocinadora desta obra, sendo significativa também a contribuição da FAPESP e do CNPq no financiamento da estrutura física interna" (CEPEA, 2016).

Apesar disso, em ediçáo de 17 de março de 2016, o Jornal de Piracicaba revelou que o centro esteve envolvido em casos de manipulação do preço do etanol, fato que teria ocorrido entre 1999 e 2000. A denúncia veio do senador Delcídio do Amaral, preso na operação "lava-jato", que informou que a manipulação visava à "obtençấo de recursos ilícitos nas operaçóes de compra de etanol” (STF, 2016, p. 188-189). No entanto, o CEPEA nega esse envolvimento, informando que não determina preços, mas sim, calcula preços médios de mercado seguindo "metodologias divulgadas abertamente que contemplam critérios estatísticos apropriados" (GERALDINI, 2016).

\section{Conclusão}

As análises realizadas apontam que a ESALQ/USP foi uma das principais bases de fomento do processo de modernização conservadora do campo brasileiro, projeto político e agrário dos militares em aliança com o empresariado nacional e multinacional. A ESALQ/USP, uma das representantes do Estado militarizado, obedeceu às políticas educacionais do regime em consonância com as exigências do modo de produçáo capitalista implantado na América Latina, numa postura de privatizaçáo do Estado, a serviço do capital e das burguesias nacionais e internacionais em prejuízo do conjunto da população trabalhadora, marginalizada e carente de direitos em um período de concentração de renda e riquezas. Grosso modo, concluímos que na ditadura civil-militar, a educação e as ciências agrárias atuaram no fomento das necessidades da ordem capitalista: a propriedade privada dos meios de produção e a concentração da riqueza, o capital.

As fontes indicam que a "Luiz de Queiroz" cumpriu um papel de destaque como fornecedora de know-how para atender às necessidades da economia nacional que se desenvolvia em uma progressiva subordinaçáo da agricultura à indústria. Por isso, a escola atendeu aos chamados governamentais e empresariais para a formaçáo de engenheiros agrônomos para atuar na área da educação, pesquisa científica e extensão rural e agroindustrial.

Para isso foi criada a pós-graduação na ESALQ em 1964, que teve sua base por meio dos convênios entre a USP e o governo dos Estados Unidos via USAID, que colocou Piracicaba em contato com a Universidade Estadual de Ohio (OSU), umas das escolas mais conservadoras dos Estados Unidos, principalmente 
na área de Ciências Sociais. Sabe-se que esse acordo entre a USP e o governo estadunidense formou a maior parte dos pesquisadores ligados ao atual agronegócio, e teve o objetivo de alinhar os pesquisadores brasileiros com a "Revolução Verde", ou seja, moldar indivíduos para aceitar e difundir o processo de modernização capitalista do campo, principalmente do ponto de vista extensionista, como foi o caso do cerrado brasileiro.

Assim, entre os anos de 1966 e 1980, a ditadura e a ESALQ/USP priorizaram encontros, congressos, palestras, simpósios, seminários e outros tipos de encontros e reunióes acadêmicas que estivessem articuladas com a genética aplicada à agroindústria, como foi a mutação genética das sementes, do milho, da soja, do trigo e galinhas; a área das tecnologias rurais, especialmente a produção de açúcar, álcool e conservaçáo de alimentos; a economia, a sociologia e as ciências sociais aplicadas, com claro objetivo de intervenção na extensão rural e o desenvolvimento da agroindústria, administração de fazendas e complexos produtivos, o ensino e pesquisa na área das ciências agrícolas e a zootecnia, via aplicação de conhecimentos agronômicos para a produção de animais e seus derivados comerciáveis, como foi a indústria de carnes.

Seja com o financiamento de algumas empresas ou com a intervenção direta do governo dos Estados Unidos, ao injetarem grande soma de dólares por meio de uma base da USAID no campus USP de Piracicaba, constatamos que, no geral, a maior parte das pesquisas no período militar foi amparada pelo Estado brasileiro com recursos públicos, em um processo de privatização do Estado, quando o aparato "público" foi usado em benefício privado de fazendeiros, empresários, financistas e industriais, com raras exceçóes. Somente entre 1979 e 1982, cerca de 80\% das pesquisas da "Luiz de Queiroz" eram financiadas com recursos público-estatais; por isso, pode-se imaginar que, sem o Estado e suas agências de financiamento de educação e ciência, o agronegócio como conhecemos hoje não existiria.

No caso da ESALQ/USP, como no de outras instituiçóes estatais, como é a EMBRAPA, formou-se um sistema nacional que se esforçou para a adaptação, criação e propagação da modernização tecnológica do campo, também conhecido como "complexo agroindustrial".

Apesar da coerção física, a ditadura conseguiu conquistar, em muitos momentos, um significativo grau de consenso entre amplos setores civis das classes médias, fato presenciado na ESALQ, quando generais como Médici e Geisel eram homenageados por alunos, professores e funcionários. $\mathrm{O}$ regime foi bem-sucedido nesse consenso, visto que beneficiou esses setores médios com ganhos, oportunidades de trabalho e esperanças de um "Brasil Potência", quando "ninguém segurava esse país" - propagandas eternizadas no coraçáo e na mente da população. Esses anseios eram materializados nas novas frentes de expansão agrícola nas regióes Centro-Oeste e Norte, mesmo que fosse um processo violento e conservador. Afinal, a modernização reproduziu elementos de "atraso" de nossa sociedade, 
como foi a eliminação física das oposiçóes políticas, o genocídio de camponeses, quilombolas e indígenas - ou mesmo a manutenção e a reprodução de uma estrutura agrária desigual, dos tempos do Brasil colônia.

\section{Notas}

1. Entidades privadas dos EUA, como a fundação Rockefeller, já vinham atuando no Brasil desde a década de 1920, fazendo a chamada filantropia científica. No entanto, a presença da USAID gerou celeuma porque implicava envolvimento oficial do governo de outro país na educação brasileira, evidentemente por interesses próprios, e não por filantropia (MOTTA, 2014, p. 110-111).

2. Esalqueanos são os estudantes, professores e funcionários da ESALQ/USP.

3. Para enfrentar a crise do petróleo da década de 1970, o Estado brasileiro criou o programa Proálcool, que incentivou o uso do álcool derivado da cana-de-açúcar como combustível para os veículos automotores.

4. As ciências aplicadas beneficiam "rapidamente" o modo de produção capitalista, desprezando as ciências "puras", que visavam a soluçóes para problemas a longo prazo, o que sempre incomodou os adeptos do imediatismo e do produtivismo acadêmico.

5. Hoje, o local se transformou no Museu "Luiz de Queiroz".

6. Para mais informaçóes sobre o conceito de "modernização conservadora" ver: Moore Junior (1975), Fernandes (1978), Mészáros (2004), Pires e Ramos (2009), Silva (1982) e Ianni (1979).

7. Por meio da operação Condor, no mesmo período, também existia um desenvolvimento coordenado de países da América Latina para a repressão de adversários políticos.

8. Além dos cursos pagos presenciais, a ESALQ/USP faz parte das instituições que estão aderindo ao conceito de ensino a distância por meio do Centro de Ensino a Distância em Ciências Agrárias (CEDECA) com os seguintes cursos: Geoprocessamento; Psicologia da Educação; Biotecnologia; Educação Alimentar.

\section{Referências}

ALMEIDA, S.M.L. Acesso à educação superior no Brasil: direito ou privilégio? Revista HISTEDBR On-line, Campinas, n. 38, p. 169-185, jun. 2010. Disponível em: <http:// www.histedbr.fe.unicamp.br/revista/edicoes/38/art13 38.pdf $>$. Acesso em: $1^{\circ}$ jan. 2016.

ASSOCIAÇÃO DOS DOCENTES DA USP - ADUSP. Segredos da Ditadura. Revista da Associação dos Docentes da Universidade de São Paulo, São Paulo, n. 33, out. 2004. Disponível em: <http://www.adusp.org.br/files/revistas/33/r33.pdf>. Acesso em: 7 mai. 2016.

BRASIL. Decreto no 5.465, de 3 de jul. de 1968. Dispóe sobre o preenchimento de vagas nos estabelecimentos de ensino agrícola, Brasília, DF, jul 1968. Disponível em $<\underline{\text { http:// }}$ www.planalto.gov.br/ccivil 03/leis/1950-1969/L5465.htm>. Acesso em: 16 fev. 2018. 
CAMPOS, P.M. Economia doméstica. Revista do Centro Acadêmico “Luiz de Queiroz”, São Paulo, 1984.

CAPDEVILLE, G. O ensino superior agrícola no Brasil. Viçosa: Imprensa Universitária (UFV), 1991.

CENTRO DE ESTUDOS AVANÇADOS EM ECONOMIA APLICADA (CEPEA). Portal. Disponível em: <https://www.cepea.esalq.usp.br/br>. Acesso em: 25 abr. 2016.

DEMÉTRIO, C.G.B.; VIEIRA, M.L.C. A pós-graduação na ESALQ: 40 anos de história. Ribeirão Preto: A. S. Pinto, 2004.

DIÁRIO. Diário de S.Paulo, São Paulo, 31 jul. 1971. Arquivo do Museu "Luiz de Queiroz" (ESALQ/USP).

. Diário de S.Paulo, São Paulo, 21 dez. 1973. Arquivo do Museu "Luiz de Queiroz" (ESALQ/USP).

ESALQ75. Escola Superior de Agricultura "Luiz de Queiroz": 75 anos a serviço da Pátria (1901-1976). Edição comemorativa. Piracicaba: ESALQ/USP, 1975.

ESTADÁO. O Estado de S. Paulo, São Paulo, 31 jul. 1971. Arquivo do Museu "Luiz de Queiroz" (ESALQ/USP).

FERNANDES, F. A condição de sociólogo. São Paulo: Hucitec, 1978.

GERALDINI, L. ESALQ é citada em delação de Delcídio. Jornal de Piracicaba, Piracicaba, 17 mar. 2016. Disponível em: <http://www.jornaldepiracicaba.com.br/cidade/2016/03/ esalq e citada em delacao de delcidio >. Acesso em: 27 ago. 2016.

IANNI, O. Ditadura e agricultura. Rio de Janeiro: Civilização Brasileira, 1979.

JORNAL DE PIRACICABA. Jornal de Piracicaba, Piracicaba, 29 jul. 1971. Arquivo do Instituto Histórico e Geográfico de Piracicaba (IHGP).

. Jornal de Piracicaba, Piracicaba, 21 de dez. 1973. Arquivo do Instituto Histórico e Geográfico de Piracicaba (IHGP).

LEÃO, R.M. Trinta anos em CENA. São Paulo: Edusp, 1997.

MÉSZÁROS, I. O poder da ideologia. São Paulo: Boitempo, 2004.

MINTO, L.W. A educação da miséria: particularidade capitalista e educação superior no Brasil. São Paulo: Outras Expressóes, 2014.

Teoria do capital humano. HISTEDBR/UNICAMP, [s.d.]. Disponível em: <http://www.histedbr.fe.unicamp.br/navegando/glossario/verb c teoria \%20do capital humano.htm>. Acesso em: 7 mar. 2016.

MOLINA, R.S. Ditadura, agricultura e educação: a ESALQ/USP e a modernização conservadora do campo brasileiro (1964 a 1985). Tese (Doutorado) - Faculdade de Educação, Universidade Estadual de Campinas, Campinas, 2016. Disponível em: <http:// repositorio.unicamp.br/jspui/handle/REPOSIP/321628>. Acesso em: 20 jan. 2018.

MOORE JUNIOR, B. As origens sociais da ditadura e da democracia: senhores e camponeses na construção do mundo moderno. São Paulo: Martins Fontes, 1975. 
MOTTA, R.P.S. As universidades e o regime militar: cultura política brasileira e modernização autoritária. Rio de Janeiro: Zahar, 2014.

PIRES, M.J.S.; RAMOS, P. O termo modernização conservadora: sua origem e utilização no Brasil. Revista Economia do Nordeste, v. 40, n. 3, jul.-set. 2009. Disponível em: <http://www.bnb. gov.br/projwebren/exec/artigoRenPDF.aspx?cd_artigo_ren=1140>. Acesso em: 7 nov. 2016.

SAVIANI, D. O legado educacional do regime militar. Cadernos Cedes, Campinas, v. 28, n. 76, set.-dez. 2008. Disponível em: <http://www.scielo.br/pdf/ccedes/v28n76/a02v2876. pdf>. Acesso em: 7 abr. 2016.

SGUISSARDI, Valdermar. Universidade, fundação e autoritarismos: o caso da UFSCar. São Paulo: Estação liberdade; São Carlos: Universidade Federal São Carlos, 1993.

SILVA, J.G. Modernização dolorosa. Rio de Janeiro: Zahar, 1982.

SUPREMO TRIBUNAL FEDERAL - STF. Direito processual penal. Investigação penal. L0604, Pet. 005952. Relator Ministro Teori Zavascki. 22 fev. 2016. Disponível em: <http://politica. estadao.com.br/blogs/fausto-macedo/wp-content/uploads/sites/41/2016/03/308950183.pdf $>$. Acesso em: 27 out. 2016.

UNITED STATES AGENCY FOR INTERNATIONAL DEVELOPMENT/ESCOLA SUPERIOR DE AGRICULTURA “LUIZ DE QUEIROZ” - USAID/ESALQ. Relatório semestral entre a United States Agency for International Development - Ohio State University e a Escola Superior de Agricultura "Luiz de Queiroz" da Universidade de São Paulo. Documento sob matrícula n. 65.1.8788.1.0, caixa 2868. Piracicaba, 1964.

UNIVERSIDADE DE SÃO PAULO - USP. Documento oficial da USP sob matrícula: $\mathrm{n}^{\circ}$ 50.063/1964. Piracicaba, 1964a.

. Documento oficial da USP sob matrícula: no 65.1.8788.1.0. Piracicaba, 1965.

. Documento oficial da USP sob matrícula: no 68.1.55287.11.4. Piracicaba, 1968.

. Documento oficial da USP sob matrícula: no 88.1.112.118. Piracicaba, $1964 \mathrm{~b}$.

Recebido em 09 de agosto de 2017.

Aceito em 22 de janeiro de 2018.

(C) 2018 Centro de Estudos Educação e Sociedade - CEDES Este é um artigo de acesso aberto distribuído nos termos de licença Creative Commons. 